\title{
A CRITICAL DISCOURSE ANALYSIS OF A VINTAGE AMERICAN AIRLINES ADVERTISEMENT
}

\author{
Nathan Dover \\ School of Humanities, Arts and Social Sciences, \\ University of New England, Australia \\ E-mail: nathanjohndover@outlook.com
}

Received: 2020-11-26

Accepted: 2021-05-31

\begin{abstract}
Critical Discourse Analysis (CDA) is a rapidly increasing area of study used by Applied Linguists to examine discourse, that is spoken or written communication, found in areas such as education, media and politics. CDA studies focus on the relationship between society and discourse and how the use of language reinforces already established societal roles. This paper focused on a vintage American Airlines advertisement of 1968 which is a classic example of utilitarian advertising that purported a false reality of air travel in the late $20^{\text {th }}$ century. Using the three-dimensional CDA framework designed by Fairclough (1989) the results showed a manipulation of gender roles by the advertisers intended to appeal to the male dominated passengers of the airline. Primarily, the alignment of air hostess with that of a mother. The maternalisation of this profession reflected the advertisers' views of the time and in a wider societal perspective, power inequalities between men and women.
\end{abstract}

Keywords: Critical Discourse Analysis, advertising, maternalisation, social hierarchy.

\section{Introduction}

The history of advertising can be traced back to ancient civilizations. But it is the explosion of capitalism, coinciding with the rise of utilitarianism in the $19^{\text {th }}$ century that was responsible for the birth of modern advertising as it is known today. In essence, utilitarian advertising focuses on what consumers need rather than what they want and targets their marketing accordingly.

In contrast, CDA has been around for a much shorter length of time. Started in the 1970s and emerging from the larger field of critical linguistics, CDA is now a multidisciplinary field of study that encompasses a wide range of social, anthropological and linguistic viewpoints concerned with various methods to study the relationship between language (discourse) and society.

Lemke (as cited in Gee and Handford, 2012) states that although CDA originally focused purely on the analysis of discourse it has grown to include a wide range of visual, animated, aural and interactive texts. With the use of multimedia discourse analysis, linguists are able to identify and explain various aspects of society being reflected and exploited in advertising such as the proliferation of normative gender roles, reinforcement of power asymmetries and sexualisation of both men and women.

This image was chosen for analysis because it represents a snapshot in time, at least from a marketing perspective. It demonstrates advertising ideology of women and their 
place in the workforce as well as the utility of American Airlines' demographic. It is also a possible indication of broader societal views of female appropriate vocations in the mid 1960s.

CDA is a form of content analysis and a single advertisement, however loaded with sociocultural discourse or sexualised imagery, does not provide enough evidence of what people actually think. Therefore, this paper will be careful not to make sweeping declarations of society's opinions more than 50 years ago based upon a single advertisement. But through CDA this paper can confidently demonstrate how advertisers created the narrative of a maternally seductive air hostess as truth, discuss why this was considered acceptable and how this representation fits into wider social practices at the time.

\section{Literature Review}

Modern advertising and sexuality is nothing new. It has pushed or at the very least, reinforced various forms of gender inequality throughout its history such as the perpetuation of unrealistic physical perfection and the reinforcement of stereotypical societal roles for both sexes.

Holbrook and Pollay (cited in Tsichila and Zotos, 2014: 447) called this the "mirror" vs. the "mold" argument. They hypothesised that whilst "mirror" advertisements purely reflect societal attitudes already prevalent in a particular culture it is the "mold" advertisements that establish these attitudes and creates the gender stereotypes that society adheres to.

Glick and Fiske (1996) theorised that female sexism in advertising can be distilled into two forms of discrimination, hostility and benevolence, in what they have coined the ambivalent sexism theory. Hostile sexism is particularly antagonistic in nature because it is seen as a power challenge to male domination and an attempt to break away from the stereotypical societal roles females are expected to adhere to. Benevolent sexism is not as antagonistic towards women but still just as prevalent in advertising. It reinforces the gender power structure of a male-centric society by placing women in subservient, domesticated positions.

In 1978 Goffman published Gender Advertisements, a highly influential book for gender portrayal analysis and theorised that "the cultural infantilisation of women and their ritualised subordination in advertisements" (Lawton, 2009:1) could be coded and placed into five categories: feminine touch, function ranking, relative size, licensed withdrawal and ritualisation or subordination. This method of examination is still used today and provides researchers with the tools to gather empirical evidence on how advertising impacts an audience, how media frames reality and the extent to which an audience will base their idea of reality on a particular advertisement.

Hovland, McMahan, Lee, Hwang, and Kim (2005) used this framework as the basis for their study into the cross cultural portrayals of women in magazines. The researchers selected two of the most widely circulated women magazines from Korea: Women's Donga (for middle-aged women) and Ceci (for young women) and from America: Good House Keeping (for middle-aged women) and Glamour (for young women). A total sample size of 320 advertisements from current issues of the magazines were randomly chosen and coded according to the framing analysis created by Goffman (1978) and were examined for implied gender roles within each country and in comparison, to the other.

The results showed a slight decrease in sexualised imagery of women in the American magazines but overall, women were still being depicted in subservient roles and although the two countries are profoundly different, the stereotypical depiction of women 
throughout all of the magazines was not pronounced. However, the researchers admit the limitations of their findings (a different selection of magazines would invariably produce different results), they concluded the study by saying that regardless of geography, advertisers use already established patriarchal gender roles in society to sell their products and "given the similarities in the American and Korean depictions of women, the Westernization of Korean advertising seems to be firmly at work" (Hovland et al. 2005: 897).

Andersson and Schytt (2017) conducted research into consumer attitudes towards companies and analysed the effect congruent and incongruent sexist advertising had on their respondents. For CDA purposes the idea of congruence (a receiver's agreeance) and incongruence (a receivers disagreeance) in relation to advertising is vital to understand the perception consumers have of a particular company. An initial survey was the interpretive method in which the primary data was collected which was then followed by a semistructured, two-part oral interview between 50 participants: 25 males and 25 females within the ages of 20-35.

The researchers used two models to interpret the data: The scale of sexism by Pingree et al. (1976) and a modified version of Goffman's (1978) original framework. In order to observe sexism in advertising, Pingree et al. (1976) created a consciousness scale that classified qualitative indicators of sexism on a scale from level one (very sexist) to level five (non-sexist). Only advertisements from the first two levels were selected for the study.

The results showed that sexist advertising had a negative influence on all participants which therefore, created a negative opinion of that company. It also discovered that women had more negative consumer attitudes than men and that regardless of gender, the most negative consumer attitudes towards companies who use sexist advertising was when the advertisements were incongruent.

However, the relatively small number of respondents and the fact that it was not a quantitative study makes it impossible to generalize on the findings and therefore it is not statistically binding.

\section{Research Method}

The research design for this CDA was based on Fairclough's (1989) three-dimensional framework of discourse analysis explained below:

1. Text Analysis: Linguistic description of text and images.

2. Discourse Practice: Interpretation of the text.

3. Sociocultural Practices: How the advertisement fits into social and cultural structures.

The aim of this study was to examine the connection between language and social practices and the extent media discourse frames these opinions or distorts them. A qualitative design research methodology was used to collect data from a single image, a vintage American Airlines magazine advertisement, produced in America and first published in October, 1968.

\subsection{Textual Analysis:}

The first stage of analysis is linguistic and examined the vocabulary, grammar, semantics and imagery of the advertisement. In the top left hand corner of the advertisement is an enlarged phrase in bold text and directly under this is the first line of text. The two sentences are as follows:

- Think of her as your mother 


\section{- She only wants what's best for you}

Through the use of personal and possessive second-person pronouns the reader is being addressed individually rather than collectively. Fairclough (1989:62) named this style of direct communication as 'synthetic personalisation' and is a common practice in marketing in order to connect with the audience. The following two lines of written discourse are three simple sentences comprised of an adjective and a noun. These sentences set the scene for potential passengers and details what to expect when they travelled on American Airlines. The sentences are as follows:

- A cool drink

- A good dinner

- A soft pillow and a warm blanket

The use of adjectives is an effective linguistic tool because it allows advertisers to emphasise the positive aspects of a product or service and implants into the minds of the receivers. Cook (2001) described this strategy as 'fusion' and noted that it will enhance a characterless product with qualities that are desirable.

The following three lines of text juxtapose the overt maternal message with one of leading-industry professionalism and culminates in a quantifying statement to ensure the reader about the competence of the stewardesses. The text is shown below:

"This is not just maternal instinct. It's the result of the longest Stewardess training in the industry. Training in service, not just a beauty course."

The text continues with guarantees regarding the service quality of American Airlines and it is this high standard that not only satisfies previous customers (resulting in repeated business) but attracts new passengers. The next two lines of text are as follows:

"Service, after all, is what makes professional travellers prefer American. And makes new travellers want to keep on flying with us."

The remaining text individualises every passenger and finishes with a declarative statement about their business ethos. For ideological and practical reasons, reassuring the reader that each and every passenger is equally important and therefore valued to American Airlines is an essential tactic to maintain credibility. Text is as follows:

"So, we see that every passenger gets the same professional treatment.

That's the American Way."

Smith (2004) noted that this style of communication in marketing is very common as it allows advertisers to establish a direct relationship between both parties. Examples of this are the pronouns "we" to imply authority and power and "you" to personally engage the audience.

Finally, the written discourse of the advertisement culminates in the company's name in bold text along with the company's slogan which reiterates the declaration of professional simplicity previously mentioned:

"Fly the American Way... American Airlines."

Occupying the majority of the advertisement is a single and commanding image of an attractive stewardess. She is curled up on a chair with her legs tucked underneath her, 
resting her head on her hand. The stewardess is directly gazing into the camera and is portraying a casual demeanor that is both seductive and relaxed. She is young and attractive. When combined with written or verbal text, visual imagery is a powerful tool in advertising and although both are effective on their own, it is the combination of the two that make for arresting and powerful discourse. This is echoed by Barthes in his essay Rhetoric of the image (1977) who argued that the interpretation of an image is always related to and dependent on some form of text to extend the meaning of the message.

The colour layout of the advertisement is best described as muted, almost monochromatic and is an important aspect of creating the professional situation described in the text. Williamson (1978) stated that "colour tells a story" and the right correlation can distill real world elements into the two dimensional. The first colour the receiver notices is the blue coat of the stewardess, the gold of her American Airlines badge and the white of her uniform. The colour scheme of her uniform depicts professionalism and sophistication. The second colour is the black text in bold. Both of the dark colours, juxtaposed against the light backdrop, draw attention to the text.

\subsection{Discourse Practices}

The second level of discourse analysis examined the discursive practices, the production and the consumption of the advertisement. Also at this stage, this paper will attempt to interpret the message of the advertisement by looking at the values and attitudes of both the producer and the audience.

American Airlines employed various discursive strategies to align this product within a social framework that allowed them to appeal to and attract a particular type of customer. Given the high cost of air travel in the 1960s, this would have been a predominantly white, affluent, upper-middle class demographic.

Blackedge (cited in Gee and Handford, 2012) in his research into power and discourse argues for the analysis of voice (spoken or written) to help identify the effects and conditions of power in discourse. The intended receiver of the advertisement must have come from a position of social-economic power and prestige. More than likely, this was a result of a high level of formal education and social opportunities afforded to a very small percentage of the American population at the time. Spoken or not, the voice of this piece of discourse in relation to its intended audience is prominent and overt.

The main theme of the advertisement is a dichotomous combination of professionalism and motherly love. These two conflicting characteristics are suggested to be in a symbiotic relationship with one another, providing the receiver with the best of both worlds when they fly American Airlines. The syntactic devices used to achieve this are a combination of visual and seductive imagery, coupled with the overall motherly and nurturing theme of the written text.

The advertisers have worked hard to balance the image of maternal care giver and professional worker in order to engage and appease the intended demographic and this is reflected in the written discourse throughout the advertisement.

The written discourse in the advertisement is gender-orientated and charged with ideology and beliefs that a stewardess's value is somewhere between professional and motherly care taker. The denotative constructs are that American Airlines stewardesses are very well trained with the longest training in the industry. Connotatively it implies that despite all this training, the stewardess is after all still a women and therefore available to nurture passengers with her maternal instincts. 


\subsection{Sociocultural Practices:}

The final level of analysis examined the wider social issues that affect marketing and the way in which advertisers use and sometimes push societal norms to sell their products.

In 1968 gender stereotypes were considerably more ingrained into the social fabric but an analysis of advertising trends suggests that regardless of how culturally dated and inappropriate this American Airline's advertisement was, the same piece of discourse could have been possible today.

In a review of 50 years of magazine articles from the United States, Mager and Helgelson (2011) concluded that although women are no longer seen entirely in domesticated settings this positive step has been negatively countered. Women are still being portrayed as reliant on a man for protection and advertisements where women are depicted as the object of sexual desire have actually increased. Despite of all the advancements in gender equality, it seems at least in Western culture, that advertising and societal views related to gender roles have not changed but simply shifted to what is considered normal at the time.

Sexual desire is not inherently a negative factor in advertising. Gill (2008) noted that there has been an increase of modernised representations of femininity. Women are no longer solely passive recipients of men's sexual desires but have taken an active role in their own sexual agency. Homosexuality is also advertised unapologetically in mainstream culture and if for nothing else, Gill states, this is culturally a significant step forward.

By combining the professionalism of the stewardess in a motherly and unassertive framework, the advertisement manages to create a feeling of warmth and gratitude, establishing an emotional connection that can be relied on whilst subtly commenting on a woman's position and her abilities in the workforce in the 1960s.

The depiction of the motherly stewardess was a clever marketing strategy that likely appealled to the intended receiver for two reasons: It reinforced the male dominated, utilitarian power structure of the time and helped to solidify the female "housebound" role regardless of professional employment.

\section{Results and Discussion}

Based on the data examined in this CDA it can be concluded that the advertisers used various tools such as direct speech, personal and possessive pronouns and declarative statements to directly address the reader and create an ideology of air travel with American Airlines in 1968. Coupled with the seductive and spatially dominating image of the stewardess, this advertisement is a classic example of misogynistic marketing that was prevalent throughout western society in the second half of the $21^{\text {st }}$ century including America.

The advertisers reduced the American Airline stewardess to an aesthetically pleasing, well-trained professional that despite all of her extensive training could not resist her womanly, maternal instincts to nurture the high paying, affluent passengers who frequented the airline.

By minimalising the power of the stewardess, the advertisers reassured the male dominated audience that despite the capability and experience of the women on board American Airlines they are, after all, only women and therefore still know their place in society. This advertisement was designed to appeal to the utilitarian needs of the intended 
demographic and marketed in a way that was professionally alluring and at the same time non-threatening.

Based on this, it can be further concluded that the narrative created by the advertisers is a wider comment on gender equality and social hierarchy prevalent at the time. This raises some questions: was this advertisement considered outrageous at the time, a gross exaggeration of the truth, or did the advertisers simply reflect what was happening in 1968 because there was enough societal evidence to support its message?

With the world left in tatters after the second world war, western governments actively encouraged the repopulation of society in what is now referred to as the baby boomer generation. Despite the advances of women entering the workforce in record numbers during the war, the majority of women willingly gave up their jobs after the war and returned to the more traditional role of housekeeper. Even if some women did want to remain in the workforce, they faced an uphill battle. On average, women earned 50-60 percent of the same wage as men did, were excluded from top well-paid jobs and faced the threat of dismissal when they got married.

The situation was made even worse with advice from the medical community that pushed the ideology of the traditional pre-war family structure. In $1957 \mathrm{Dr}$. John Schindler published The Woman's Guide to Better Living 52 Weeks a Year, in which he wrote "Whether you are a man or woman, the family is the unit to which you most genuinely belong. The family is the center of your living. If it isn't, you've gone astray."

This sentiment was echoed by one of the leading childcare experts of the day, Dr. Benjamin Spock in his best-selling book Common Sense Book of Baby and Child Care. First published in 1946, it continued to be highly influential for years. In it Spock warned mothers that employment and even hobbies were nothing more than distractions that were potentially harmful to a young child and advised mothers to devote themselves full-time to raising their children.

Considering this historical context, the decision to align American Airlines' stewardesses with that of a motherly caretaker by the advertisers is easier to understand. Despite an increase of women in the workforce by the time of publication (the American department of labor estimated an 11\% increase for female employment from 34\% in 1950 to 43\% in 1970), working in America in 1968 was still a male dominated area.

Regardless of these facts, it is evidently clear that the advertisers took a subjective artistic license when they reduced and demeaned the professionalism of American Airlines' stewardesses to that of a glorified housewife in an attempt to entice and appease to their male dominated demographic.

\section{Conclusion}

The purpose of this CDA was not to make broad sweeping statements of societal views in 1968 but attempt to explain the meaning behind American Airlines' message and how an advertising firm could release a piece of discourse such as this. By examining the context of discourse, linguists can understand language and its connection between social, power, gender and racial relations, many of which are hidden in layers of nuanced discourse throughout the majority of past and modern advertising.

The overt language that was used and the underlying subtext and connotative message behind it, coupled with the seductive and sexualized imagery of the advertisement presented the narrative that at American Airlines, passengers got the best of both worlds: unparalleled hospitality from an attractive and possibly flirtatious stewardess who would 
simultaneously mother them and cater to their every domesticated whim. The combination of these diametrically opposed societal positions clearly demonstrates American Airlines' view of women who were working in their company at the time and in a broader sense, it made a not-so-subtle comment on a women's place in society.

In 2021 it would be congenial to think that advertising and society in general has moved on from such sexist and demoralizing representations of women like the one found in this advertisement. Further research should be conducted on a wider range of advertisements across a broad section of magazines to ascertain if this is the case as a CDA on a single piece of marketing is not adequate enough to make any claims in regards to realistic female depictions in advertising.

It is true that women have more vocational freedom than ever before and slowly but surely, there is a cultural shift towards economic and social equality between men and women. Hopefully with this shift, female roles in the workforce will be represented more truthfully and companies have surpassed the need to use the archaic ideology and chauvinistic discourse displayed by this American Airlines advertisement.

\section{References:}

Andersson, H. \& Schytt, E. (2017). Sexism in Advertising: A Qualitative Study of the Influence on Consumer Attitudes Towards Companies: Master Thesis in Business Administration. Retrieved from

https://www.diva-portal.org/smash/get/diva2:1105334/FULLTEXT01.pdf.

Barthes, R. (1977) Rhetoric of the Image. Retrieved from http://huma1970a.blog.yorku.ca/files/2010/04/Barthes_Rhetoric-of-the-image.pdf.

Cook, G. (2001). Discourse in Advertising. London, England: Psychology Press.

Fairclough, N. (1989) Language and Power. London, UK: Longman.

Gee, J.P., \& Handford, M. (2013). The Routledge Handbook of Discourse Analysis. New York, U.S.A: Routledge.

Gill, R. (2008) Empowerment/Sexism: Figuring Female Sexual Agency in Contemporary Advertising. Feminism and Psychology, 18(1), pp. 35-60. doi: 10.1177/0959353507084950.

Glick, P., \& Fiske, S. T. (1996) The Ambivalent Sexism Inventory: Differentiating Hostile and Benevolent Sexism. Journal of personality and social psychology, 70(3), 491.

Goffman, Erving. (1978). Frame Analysis. https://doi.org/10.1177/004839317800800108.

Hovland, R., McMahan, C., Lee, G., Hwang, J. S., \& Kim, J. (2005). Gender Role Portrayals in American and Korean advertisements. Sex Roles, 53(11), 887-899.

Lawton, E. (2009) Gender Advertisements: Replication of a Classic Work Examining Women, Magazines and Facebook Photographs. Retrieved from www.core.ac.uk/download/pdf/56727887.pdf.

Mager, J., Helgeson, J.G. (2011). Fifty Years of Advertising Images: Some Changing Perspectives on Role Portrayals along with Enduring Consistencies. Sex Roles, 64, 238-252. https://doi.org/10.1007/s11199-010-9782-6.

Pingree, et.al. (1976). A Scale for Sexism. https://doi.org/10.1111/i.14602466.1976.tb01958.x.

Williamson, J. (1978). Decoding Advertisements (Vol. 4). London, England: Marion Boyars 
Tsichla, E. \& Zotos, Y.C. (2014). Female Stereotypes in Print Advertising : a Retrospective Analysis. Procedia-social and behavioral sciences, 148, 446-454

Schindler, J.A. (1957). Woman's Guide to Better Living 52 Weeks a Year. N.J., U.S.A: Prentice Hall Inc.

Smith, K. (2004). I Am Me, but Who Are You and What Are We: The Translation of Personal Pronouns and Possessive Determiners in Advertising Texts. Retrieved from https://www.degruyter.com/document/doi/10.1515/mult.2004.013/html

Spock, B. (1946). The Common Sense Book of Baby and Child Care. New York City, U.S.A: Duell, Sloan and Pierce 